\title{
Construção e desaparecimento do herói: uma questão de identidade nacional
}

\section{OLGÁRIA CHAIN FÉRES MATOS}

"Os homens crêem que o instante terminal de sua vida libera, por si só, uma mensagem: a morte seria o momento de revelações, momento solene por recapitular o passado e pela novidade desconhecida de que é portadora. É o fim que, retrospectivamente, ilumina com uma súbita claridade uma vida inteira, de agora em diante, terminada, consagrando-lhe valor (...). Só a morte transforma uma vida em destino" (Jankélévitch, 1980, p 138).

\begin{abstract}
RESUMO: O ensaio procura compreender a emergência e a desconstrução do herói e do heroísmo no horizonte da morte, segundo o mito da invulnerabilidade e da fantasia do renascimento que vence a brevidade da vida. Fator de convergência de identidades imaginárias, sua sobrevivência torna-se problemática na modernidade, regida esta pela conversão do herói em espetáculo televisivo momentâneo, de tal forma que se configura uma alucinação negativa, a ausência da representação do direito a ter direito no processo de dessocialização no mundo contemporâneo.
\end{abstract}

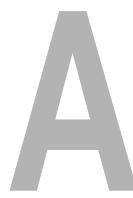

s muralhas de Tróia, nos conta Homero, viram Heitor fugindo de Aquiles, mas eis que, subitamente pára. Sabe que vai morrer. O destino de morte (moîra) apoderou-se dele, os deuses o abandonaram. Se já não lhe é dado vencer e sobreviver, dele depende, no entanto, cumprir sua condição de guerreiro: transformar sua morte em glória imperecível, fazer do lote comum a todas as
UNITERIMOS:

herói, heroísmo, morte, invulnerabilidade, alucinação negativa.

Professora do Depto. de Filosofia da FFLCHUSP 
criaturas sujeitas ao traspasso um bem que lhe seja próprio e cujo brilho seja eternamente seu. É conhecido o ideal da cultura grega arcaica, a um só tempo, ético, estético e guerreiro. Existe um modo heróico de morrer: aquele que se dá em combate, na flor da idade - a vida breve: "a lógica da honra heróica é a do tudo ou nada (...) Se Aquiles não for reconhecido como o primeiro e, de certo modo, o único, sente-se reduzido a nada" (Vernant, 1979, p. 36).

Existe, no personagem de Aquiles, duas honras: a timé comum, o reconhecimento da opinião pública, disposta a celebrá-lo e uma outra - a glória imorredoura que o destino lhe reserva. (...). A pronta morte, quando assumida, tem sua contrafação: glória imortal, aquela que a gesta heróica louva. Ultrapassa-se a morte acolhendo-a ao invés de a sofrer, tornando-a a aposta constante de uma vida que toma, assim, valor exemplar e que os homens celebrarão. A verdadeira morte é o esquecimento, a obscura indignidade, a ausência de fama: "pelo canto público dos feitos aos quais se deu por inteiro, o herói continua, além da morte, presente, a seu modo, na comunidade dos vivos (...)". A vida breve, a façanha, a bela morte possuem papel de paidéia, de formação, com os valores, crenças, atitudes, de que é feita uma cultura. O desejo de glória imperecível é, também, ultrapassar a velhice. A morte e a idade avançada equiparam-se para os gregos: "aos olhos dos homens vindouros a dos jovens, ao contrário memória os habitará, afixada no fulgor de uma juventude definitiva" (Vernant, 1979, p. 44). "A morte violenta, bela e gloriosa quando inteiramente jovem, eleva o herói acima da condição humana: arranca-o do traspasso comum conferindo a seu fim um caráter de sublimidade fulgurante" (p. 50). Bela, a morte heróica é celebrada na cadeia contínua das gerações vindouras. A biografia que a morte conclui a torna inalterável. Tornada lendária, a figura do herói tece uma tradição.

Não é este, no entanto, o único significado do herói. No dicionário grego-francês Bailly temos que o termo herói vem do grego (Eros) e, num primeiro sentido significa, como vimos, o Mestre, o chefe nobre, chefes militares gregos que combateram em Tróia. Por extensão, é herói todo combatente, nobre por nascimento e consangüinidade, pela coragem e talento. Em um segundo sentido, herói é o semideus, situado entre os deuses e os homens, como Héracles (Hércules); e, por fim, todo homem elevado à condição de semideus como, por exemplo, os imperadores romanos divinizados.

Detectamos, nos três sentidos, a idéia de que o herói é aquele que detém, suspende o tempo e que por sua excelência supera, por assim dizer, a condição humana.

Sabemos que, entre nós, o mais recente que se investiu de todas essas características foi Ayrton Senna que, à semelhança do herói grego, pretendia "superar-se a si mesmo", no horizonte da morte iminente (cf. Rank, 1993 e Freud, 1980, último capítulo). 
Para Rank, a situação originária do trauma do nascimento foi vencer um duplo risco: a hostilidade paterna quando ainda na vida uterina, e o ato do nascimento, pelo qual se separa da mãe e no qual o medo da morte se atestaria pela dispnéia do recém-nascido. O herói é aquele que entra no perigo, pois só assim conquista seu ser. Nada seria se se furtasse a ele. É na iminência da morte e no risco que ele se reconhece, em sentido próximo ao das reflexões de Otto Rank. Ultrapassando o medo da morte, por seus atos, o herói substitui compensatoriamente o medo. Liberta-se da ansiedade da separação e do medo da morte pela repetição de feitos arriscados tendo sua garantia de sobrevivência fundada numa "fantasia de renascimento e de invulnerabilidade".

Da idéia do herói que é uma memória coletiva, podemos derivar para aquela de procura de uma identidade de si mesmo. Pode-se também falar em herói ou instituições heróicas que confiram referência estável, permanente. Elias Canetti (1966), estabelece, para pensar as "instituições heroicizadas" em relação à identidade nacional, as noções de massa aberta e "massa fechada": "o que impacta primeiramente (na massa fechada) é o limite. (...) Ela se dá seu lugar se limitando: o espaço que ocupará lhe é assinalado (p. 14), como o exército, a igreja; quanto à 'massa aberta', ela é o crescimento ilimitado, quando os homens rejeitam aquilo que os separa e se sentem todos iguais" (p. 15). Canetti amplia a concepção freudiana de massa fechada na identificação narcisista, medindo-a pelos símbolos nacionais. No que se refere, por exemplo, aos ingleses: "todo o mundo sabe o que é o mar para o inglês (...). $\mathrm{O}$ inglês se vê capitão com um pequeno número de pessoas em um barco, a seu redor e sob ele o mar (...). Quanto ao mar, ele é dominado, eis a representação capital (...). A rota que segue é a ordem que (o capitão) dá ao mar, é propriamente o mar que deve lhe obedecer" (p. 181-182). Quanto aos holandeses: aparentam-se aos ingleses pela semelhança da língua e pela idêntica evolução religiosa. São duas nações marítimas que fundaram impérios de além-mar: "o destino de um capitão holandês que ia ao mar para a descoberta e o comércio não se distinguia em nada de um capitão inglês. As guerras que travavam faziamse entre parentes próximos rivais. Há, no entanto, uma diferença que pode parecer insignificante, mas que é essência, a de seus símbolos de massa nacionais. $\mathrm{O}$ inglês só tem seus barcos para submeter o mar, o capitão comanda o mar. $\mathrm{O}$ holandês necessitou começar por arrancar ao mar as terras que habita. Elas eram tão baixas que precisou protegê-las do mar por diques. O dique é o alfa e o ômega de sua vida nacional. A massa dos homens se identifica a si mesma com o dique; unem-se para se opor ao mar. Se os diques são danificados, o país está ameaçado" (p. 182-183). Quanto aos alemães: "o símbolo de massa dos alemães é o exército. Mas o exército era mais que o exército: era a floresta em marcha. Nenhum país moderno (...) guardou tão vivamente quanto a Alemanha o sentimento da floresta. $\mathrm{O}$ paralelismo rígido das árvores (...), sua densidade e seu número 
preenchem o coração do alemão com uma alegria profunda e misteriosa. Mesmo em nossos dias, ele se jubila em visitar a floresta na qual viveram seus ancestrais e se sente unido às árvores.

A nitidez das árvores, bem delimitadas (...), sua verticalidade marcada, distinguem esta floresta da selva tropical onde as lianas se mesclam em todos os sentidos. Na floresta horizontal, o olhar se perde à pequena distância, é uma massa caótica, desarticulada, animada por uma vida extremamente variada que exclui qualquer sentimento de regra e de retorno regular. A floresta da zona temperada tem um ritmo evidente. $\mathrm{O}$ olhar, seguindo os troncos bem visíveis, se perde em um longínquo sempre igual" (Canetti, 1966, p. 183).

Canetti escreve ainda que o exército no qual serviram os jovens alemães tinha uma função de massa fechada; porém, a devoção ao serviço militar ultrapassava as religiões tradicionais, abarcando tanto católicos como protestantes. Quem se excluísse do exército não era alemão: "Quando explodiu a Primeira Guerra Mundial, o povo alemão inteiro se transformou em uma só e única massa aberta" (p. 191). Segundo Canetti, o grande êxito de Hitler se funda no Tratado de Versailles. A sociedade se militarizou. Hitler desejava uma Alemanha que se voltasse às glórias do passado, consciente de sua força militar de choque, identificada com ele: "mas jamais Hitler teria atingido o alvo se o Tratado de Versailles não tivesse dissolvido o exército alemão. A interdição do serviço militar obrigatório frustrou os alemães de sua massa fechada mais importante (...). Sua interdição é o nascimento do nacional-socialismo. Toda massa fechada dissolvida pela força se transforma em massa aberta à qual transmite todas as suas características. O Partido toma o lugar do Exército, e nenhum limite lhe é imposto no seio da nação. Todo alemão, homem, mulher, criança, soldado ou civil, pode ser nacional-socialista; freqüentemente, prende-se a ele tanto ele próprio não foi soldado, porque é para ele o meio de participar de uma conduta que lhe era normalmente recusado" (Canetti, 1966, p. 50).

Versailles tem, segundo Canetti, várias significações: foi aí que Bismarck fundou o segundo Reich alemão, a unidade alemã sendo fivelada imediatamente após uma vitória, num momento de exaltação e potência irresistível - vitória sobre Napoleão III, "sucessos de Napoleão, o Grande". Versailles era ainda a morada de Luís XIV, aquele que, antes de Napoleão, humilhava mais profundamente os alemães: "Ele é quem incorporava Estrasburgo à França, com sua catedral, suas tropas devastaram o Castelo de Heildelberg" (p. 153).

Também a proclamação do Imperador em Versailles foi como que uma vitória tardia e global sobre Luís XIV e Napoleão, conquistado pelos aliados: "pode-se dizer, sem exagero, que todas as grandes palavras de ordem do nacional-socialismo, com exceção daquelas que diziam respeito aos judeus, podem-se deduzir do estilhaçamento do tema Diktat de Versailles: A derrota que deve se transformar em vitória, o exército proibi- 
do que importa antes de mais nada reconstituir com vistas a esse fim" (Canetti, 1966, p. 194): o exército heróico.

Herói ou instituições heróicas são fonte de identificação imaginária ou, em outras palavras, de identidade coletiva. O heroísmo convertido em espetáculo pela mídia, porém, tende a dissolver a memória, a recordação heurística e ativa, a reminiscência identificadora de um nós social. Isto porque a mídia transforma a morte - horizonte do heroísmo - em espetáculo, isto é, em entretenimento, tal como pudemos assistir, pela T. V., à agonia, paixão e morte de Ayrton Senna.

De início, espetáculo e especulação possuem raiz comum: "espetáculo e especulação possuem a mesma origem e estão ligados à idéia do conhecimento como operação do olhar e da linguagem. A cultura está impregnada de seu próprio espetáculo, do fazer ver e do deixar-se ver. A questão não se coloca diretamente sobre o espetáculo, mas com o que com ele sucede quando capturado, produzido e enviado pelos meios de comunicação de massa" (Chaui, 1992).

A missa oficiada ao herói Ayrton Senna teve como co-oficiantes holofotes, microfones, câmeras de TV, fotógrafos, repórteres, técnicos, operadores de máquinas: "além de interceptarem a concentração e mediação dos presentes, os noticiadores tornaram-se oficiantes (...) só que de outra cerimônia, falando ao mesmo tempo que o sacerdote (...) narrando aos que ficaram em casa o que se passava no cemitério" (Chaui, 1992). Para o fiel, o instante máximo do Réquiem foi o de profanação absoluta, perdeu sua dignidade. O que assistiram aos rituais fúnebres, viram o fantasma da missa, seu simulacro. A missa mortuária foi transformada em entretenimento público, a dor exposta em estetização.

Ainda a identidade:

Sérgio Buarque de Holanda, em sua Raízes do Brasil diz que, se identidade há, a nossa, ao contrário das européias, é bovaristal. Esse "mal" não teria diminuído com o tempo, "O que diminuiu foi nossa sensibilidade a seus efeitos".

No dicionário Petit Robert lê-se: "bovarismo: 1865: de Madame Bovary, romance de Flaubert. Evasão no imaginário para a insatisfação romanesca; poder do homem de se conceber outro do que se é". Trata-se de um "singular poder de metamorfose", uma espécie de "falha" lacunar da personalidade, tal como se vê em todos os personagens de Flaubert, falha em se conceber outro com respeito ao que se é. Nesse aspecto, "o suicídio de Emma Bovary se dá ao reconhecer sua impotência para modificar o mundo externo, pagando com a vida este erro crítico ao se ter concebido diferentemente do que era, nessa presunção idealista de ter procurado submeter o real ao imaginário".

Apoiados nessa perspectiva, poderíamos dizer que "todos não nos concebemos diferentes do que somos". Tornamo-nos de um jeito ou outro, segundo sugerem, hipnoticamente, as circunstâncias. Esta seria a
${ }^{1}$ Conferir a pesquisa de Eliana Maria de Melo Souza (em andamento). 
característica básica do que se costuma tratar pela "adaptabilidade" e sua versatilidade.

Assim, também, para Sérgio Buarque, o bovarismo é um "modo de ver" ou um "método" daqueles que se recusam à "realidade" e que imaginam o Brasil diferente do que é (não um Brasil de negros, mulatos, incultos e, por assim dizer, pré-cidadãos, por exemplo), mas branco, liberal, europeu ou americanizado, "país grande e do futuro".

Pode-se medir o grau de afastamento ou de aproximação entre real e imaginário, numa espécie de "indicador bovárico" entre o que se é e o que se acredita ser, o que pode conduzir a uma total desagregação: "o bovarismo ideológico com nefastas conseqüências consiste em que uma coletividade toma como verdade universal uma atitude que só é própria a outra coletividade determinada. Esse 'bovarismo de desenraizados' parece ser a precária identidade brasileira com seus mitos e heróis de circunstância, sem circunscrição ou memória duradoura" (Souza, 1992).

Nessa fronteira entre um Brasil que vota branco ou nulo (39\%) que reconhece de maneira latente ou manifesta a ociosidade, indolência e patrimonialismo dos representantes públicos como "donos do poder" e outro que vota $25 \%$ em Lula, apesar do preconceito social, da desqualificação pública de competência, de um ideário que converte direito em privilégio, o Brasil tende a confirmar esse bovarismo: país que, a um só tempo, - cria o imaginário de um "país do futuro" com um desejo de enraizamento mas que está expulso não de uma tradição, mas de qualquer tradição.

Nesse sentido, poderíamos, no momento concluir no empobrecimento espiritual das democracias, a partir do que se constrói uma espécie de "cidadania negativa", aquela do "não-direito", os heróis que povoam nosso imaginário acabam no que Marx escrevia no Dezoito Brumário: "paixões sem verdade, verdades sem paixão, heróis sem heroísmo, história sem acontecimentos".

O herói moderno parece não ter garantida sua imortalidade pela rememoração, pela recordação, pois não chega a nos conferir a procurada identidade. Bovarismo significa, assim, uma espécie de "alucinação negativa". Se na alucinação produzimos a presença de um objeto ausente, na alucinação negativa, na presença do objeto alucinamos sua ausência, isto é, não o vemos, não o reconhecemos: "compreendemos a alucinação negativa”, escreve André Green, "não como a ausência de representação, mas como representação da ausência de representação, aquela que espera algo que não vem". Ocorreria aqui uma realidade vista como recoberta e deslocada. Existiria um objeto de desejo (um país justo) e um desejo de objeto (que não se sabe exatamente qual é), e o sujeito tem que se situar na diferença entre ambos. A angústia em ignorar-se quem se é e o que se é leva a uma perturbação da identidade e das identificações que só adquirem pertinência em relações entre si. Há identificações contraditórias e a iden- 
tidade de um Sujeito é sempre imaginária: "a imagem que forma de si nunca pode coincidir com ela mesma, devido à alteridade que a habita" (Green, 1982, p. 237). Essa identificação de si só pode se desenvolver separando-se de uma parte de si.

Identificação são resultados de incorporações de objetos e introjeções de afetos a eles ligados. Ali onde a imagem do Sujeito (de um Brasil) deveria surgir, nada se mostra (como em um herói): "só é visível um espelho no qual nenhum traço se inscreve". O Sujeito vive a ausência de si; o que falta ao Sujeito não é o sentimento de sua existência, mas sua prova especular. Esta ausência de representação do Sujeito é semelhante à angústia de uma perda. Não há como reconhecer uma representação, falta o poder de imaginar, de representar. Não é possível nenhum apoio, visto que o espelho devolve seu próprio reflexo vazio: "o outro que sou não aparece mais". O eu passa a se procurar em toda parte, em qualquer parte, em torno de si, buscando uma "imagem perdida" (Green, 1982, p. 238239). Ou nas palavras de Flávio Aguiar: "nós já fomos quase tudo na vida: um outro sem eu; um eu perseguido pelos (seus) outros; um eu que na verdade era outro, ou um outro que na verdade era eu, filhos de um espaço controverso e convulso onde de repente todo mundo era do mundo todo; nós já fomos um nós em busca deles que deveriam ser nós; ou que nós deveríamos ser; agora penso (logo hesito) - somos um nós, paciente da anomia redentora em busca de um eu que passou e nos espera, de uma outra margem, de uma ilha afortunada que não sabemos qual seja, e cujo olhar já cego para as coisas deste mundo nos encara com sua ironia civilizadora" (Aguiar, 1985).

Trocamos, talvez, uma identidade palpável, por outra "polifônica", onde diversos eus são suscitados, de tal forma que à "amnésia coletiva" respondem imaginários que se investem com novos heróis e novos mitos.

Recebido para publicação em abril/1995

MATOS, Olgária Chain Féres. The building and deconstruction of the hero: a matter of national identity.

Tempo Social; Rev. Sociol. USP, S. Paulo, 6(1-2): 83-90, 1994 (editado em jun. 1995).

ABSTRACT: The essay tries to understand the emergence and deconstruction of both the hero and heroism in the realm of death, according to the myth of invulnerability and fantasy of rebirth that strikes life's briefness. As a point of convergence for imaginary identities, its survival becomes a problematic issue for modernity, which is ruled by the hero's conversion into a transient TV show, as to configure a negative delusion, that is, the absence of representation of

UNITERIMS:

hero, heroism, death, invulnerability, negative delusion. rights to the process of desocialization in the contemporary world. 


\section{REFERÊNCIASBIBLIOGRÁFICAS}

Aguiar, Flávio. (1985) Os enredos da cultura brasileira. Revista do Brasil. Rio de Janeiro, Ed. Secretaria da Ciência e Cultura do Governo do Estado do Rio de Janeiro e da Prefeitura do Município do Rio de Janeiro, ano II, $\mathrm{n}^{\mathrm{o}} 4$. Apud CARDOSo, Irene Ribeiro de Arruda. (1988) Os acontecimentos de 1968. Notas para uma interpretação. In: SANTos, Maria Cecília Loscchiavo dos. Maria Antonia: uma rua na contramão. São Paulo, Nobel.

CAnetti, Elias. (1966) Masse et perissance. Paris, Gallimard.

Chauı, Marilena. (1992) Mídia e democracia. Aula inaugural. São Paulo, Departamento de Filosofia, FFLCH-USP (mimeo).

Freud, Sigmund. (1980) A psicopatologia da vida cotidiana. In: . Obras psicológicas completas de Sigmund Freud. Edição standard brasileira, vol. VI. Rio de Janeiro, Imago.

Green, Andre. (1982) O discurso vivo, uma teoria psicanalítica do afeto. Rio de Janeiro, Francisco Alves.

Holanda, Sérgio Buarque de. (1979) Raízes do Brasil. Rio de Janeiro, Livraria José Olympio Editora.

JankÉLÉvitch, V. (1980) La réconnaissance. Paris, Éditions du Seuil.

RANK, Otto. (1993) The trauma of birth. New York, Dover Publications Inc.

SouzA, Eliana Maria de Melo. (1992) Relatório de atividades. Araraquara, Departamento de Sociologia, FCL-Unesp (mimeo).

. (pesquisa em andamento). Itinerários de uma obra - Raizes do Brasil como fonte de investigação e interpretação. Araraquara, Departamento de Sociologia, FCL-Unesp.

VERNANT, J. P. (1979) A bela morte e o cadáver ultrajado. Revista discurso. São Paulo, no 9, p. 31-62. 